\title{
Proportion and risk indicators of nonadherence to antihypertensive therapy: a meta-analysis
}

\author{
This article was published in the following Dove Press journal: \\ Patient Preference and Adherence \\ 13 February 2014 \\ Number of times this article has been viewed
}

\section{Mark Lemstra \\ MWasem Alsabbagh}

Academic Family Medicine, College of Medicine, University of Saskatchewan, Saskatoon, SK, Canada
Correspondence: Mark Lemstra Academic Family Medicine, College of Medicine, University of Saskatchewan, I 10 Science Place, Saskatoon, SK S7N 5C9, Canada

$\mathrm{Tel}+\mathrm{I} 3069662108$

Fax + I 3069666377

Email mark.lemstra@usask.ca
Purpose: The World Health Organization (WHO) concluded that poor adherence to treatment is the most important cause of uncontrolled high blood pressure, with approximately $75 \%$ of patients not achieving optimum blood pressure control. The WHO estimates that between $20 \%$ and $80 \%$ of patients receiving treatment for hypertension are adherent. As such, the first objective of our study was to quantify the proportion of nonadherence to antihypertensive therapy in real-world observational study settings. The second objective was to provide estimates of independent risk indicators associated with nonadherence to antihypertensive therapy.

Materials and methods: We performed a systematic literature review and meta-analysis of all studies published between database inception and December 31, 2011 that reviewed adherence, and risk indicators associated with nonadherence, to antihypertensive medications.

Results: In the end, 26 studies met our inclusion and exclusion criteria and passed our methodological quality evaluation. Of the 26 studies, $48.5 \%$ (95\% confidence interval $47.7 \%-49.2 \%$ ) of patients were adherent to antihypertensive medications at 1 year of follow-up. The associations between 114 variables and nonadherence to antihypertensive medications were reviewed. After meta-analysis, nine variables were associated with nonadherence to antihypertensive medications: diuretics in comparison to angiotensin-converting enzyme (ACE) inhibitors and angiotensin receptor blockers (ARBs) and calcium channel blockers (CCBs), ACE inhibitors in comparison to ARBs, CCBs in comparison to ARBs, those with depression or using antidepressants, not having diabetes, lower income status, and minority cultural status.

Conclusion: This study clarifies the extent of adherence along with determining nine independent risk indicators associated with nonadherence to antihypertensive medications.

Keywords: meta-analysis, antihypertensives, adherence

\section{Introduction}

In a comprehensive report on nonadherence to long term therapies, the World Health Organization (WHO) stated that treatment of hypertension can reduce the risk of stroke by $30 \%-43 \%$ and myocardial infarction by $15 \%$, along with reducing the risk of a number of other chronic conditions. ${ }^{1}$ Similarly, in a meta-analysis of 147 randomized trials, the authors found that patients who received treatment with antihypertensive medications observed a $22 \%$ reduction in coronary heart disease events and a $41 \%$ reduction in stroke. ${ }^{2}$ However, the WHO also concluded that poor adherence to treatment is the most important cause of uncontrolled high blood pressure, with approximately $75 \%$ of patients not achieving optimum blood pressure control. ${ }^{1}$ The implications are vast. A meta-analysis on interventions for enhancing medication adherence completed by the Cochrane Collaboration concluded that effective ways to help patients follow medical 
treatments could have far larger effects on health outcomes than any individual treatment by itself. ${ }^{3}$ For example, one review estimated that better adherence to antihypertensive therapy could prevent 89,000 premature deaths in the US alone on an annual basis. ${ }^{4}$

In a meta-analysis on proportion and risk indicators for statin therapy, the authors found that only $49 \%$ of patients are adherent in real-world observational studies. After reviewing 147 variables, only six covariates were found to be independently associated with nonadherence to statin therapy: primary prevention, new statin users, copayment, lower income status, fewer than two lipid tests performed, and not having a comorbidity of hypertension. ${ }^{5}$

To date, a systematic literature review and meta-analysis has not been performed on the extent of nonadherence to antihypertensive therapy. As such, the WHO had to estimate that between $20 \%-80 \%$ of patients receiving treatment for hypertension are adherent. ${ }^{1}$ In other words, the true extent of nonadherence is not known and is a justification for this review.

The WHO also concluded that there is an urgent need for research to fill gaps in knowledge on the determinants of adherence. ${ }^{1}$ Two systematic reviews have been published on variables associated with nonadherence to antihypertensive therapy. The first reviewed the impact of depression, but included self-report adherence information. ${ }^{6}$ The second reviewed differences in adherence between angiotensin receptor blockers (ARBs) and other antihypertensive drug classes. However, the authors used filters to limit the search strategy and excluded studies that used a single point in time (ie, 1 year) to define adherence. ${ }^{7}$ As well, both studies modified established quality-assessment rating checklists for their quality review. 6,7

The first objective of our study was to quantify the proportion of adherence to antihypertensive therapy in real-world observational study settings. The second objective was to provide estimates of independent risk indicators associated with nonadherence to antihypertensive therapy.

\section{Materials and methods}

We performed a systematic literature review of electronic databases: Medline (Ovid), Embase (Ovid), International Pharmaceutical Abstracts (Ovid), the Cochrane Library, Cumulative Index to Nursing and Allied Health Literature (CINAHL), PsycINFO, Sociological Abstracts (ProQuest), ProQuest Dissertations and Theses, Theses Canada, and OAIster from inception to December 31, 2011. Multiple combinations of search terms and keywords were used to maximize the ability to capture relevant articles. Papers that were not published electronically were not included in our search. Reference sections of each article were reviewed for additional papers (Figure 1).

Studies were included if they satisfied the following criteria: 1) nonadherence to antihypertensive medications as an outcome, 2) antihypertensive medications included angiotensin-converting enzyme inhibitors (ACEIs), ARBs, beta blockers, calcium channel blockers (CCBs), or thiazide diuretics for any indication, 3) dispensation records as the source of objective nonadherence information, 4) conducted multivariable modeling to determine the independent effect of covariates on the outcome of nonadherence, and 5) published in the English language.

Abstracts and full-text articles were assessed by two reviewers for relevance (MWA and ML). Study quality was reviewed with a checklist developed by the International Society for Pharmacoeconomics and Outcomes Research (ISPOR) for database studies. The checklist was developed for the specific purpose of critically evaluating the unique complexity of administrative datasets analyzing medication adherence. ${ }^{8,9}$ This checklist has been used in other systematic reviews. ${ }^{10}$ It consists of 27 quality-review questions related to data source, research design, study population, variable definitions, statistics, and discussion. We established a rule a priori that studies scoring 14/27 or higher (greater than 50\%) on the quality checklist would be included in the meta-analysis, unless there was a major methodological violation.

Disagreement between the two reviewers was resolved by additional review and discussion, and then, if required, with the senior author (ML) making a final decision. We assessed agreement between reviewers with $\kappa$-statistics. ${ }^{11}$

We conducted a random-effects model meta-analysis using the inverse-variance method to estimate the effect of a risk indicator on medication adherence. A random-effects model accounts for potential heterogeneity between the populations and unmeasured confounding. ${ }^{12-15}$ Given that rates of adherence were being compared, rate ratios (RRs) were computed instead of odds ratios. Four or more articles were required for meta-analysis.

Sensitivity analysis reviewed the individual influence of a study by repeating the meta-analysis without studies with the largest and smallest relative weights. If this produced little change in inference (less than $15 \%$ change in rate ratio), inclusion of the study would not warrant caution in the interpretation. Sensitivity analysis also included country of origin and measures used to calculate adherence. We used the $Z$-test for overall effects and the $\chi^{2}$ statistic to test for differences 


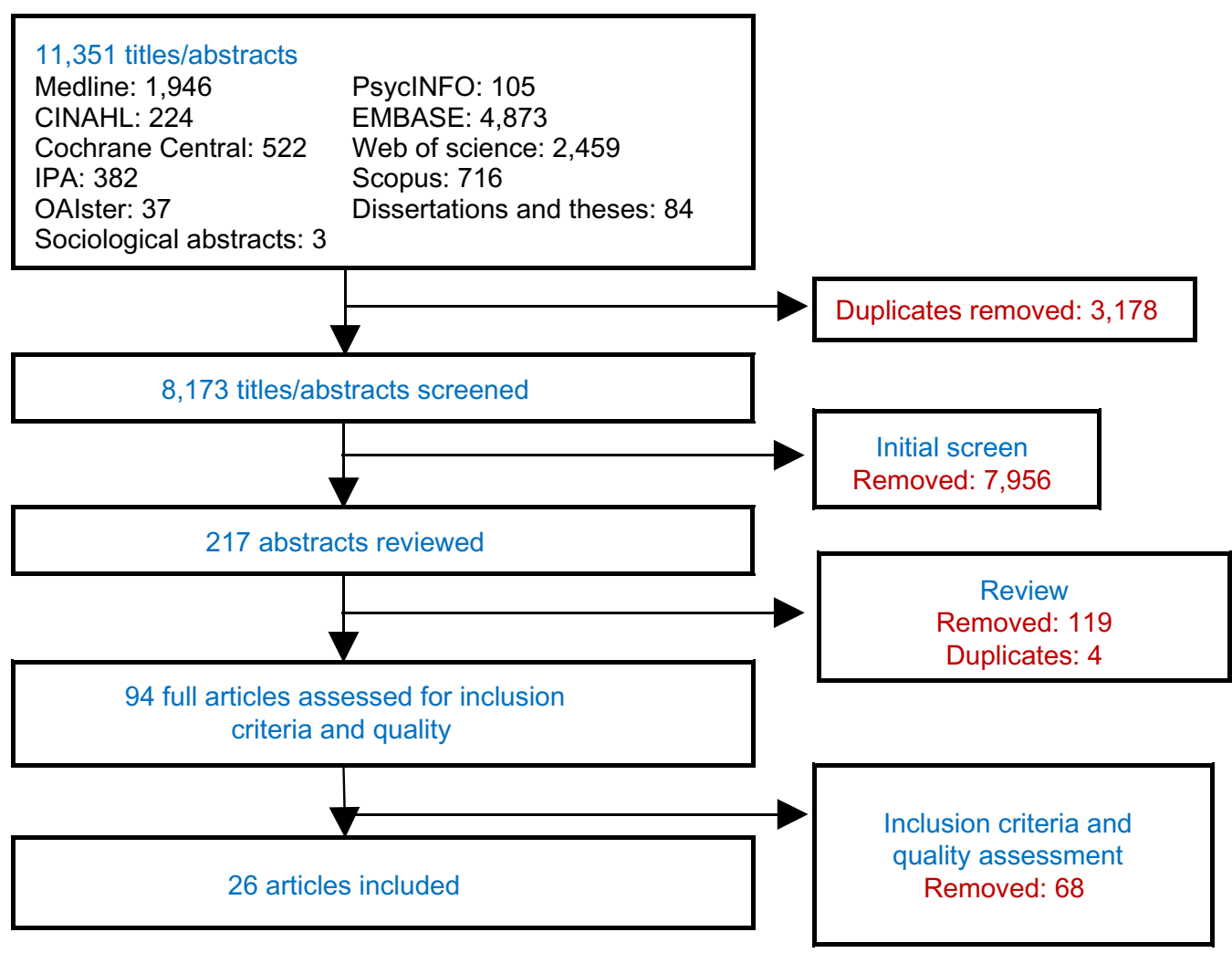

Figure I Systematic literature-review process.

Abbreviations: CINAHL, Cumulative Index to Nursing and Allied Health; IPA, International Pharmaceutical Abstracts; OAlster, Open Archives Initiative.

in between-group effects. We included every risk indicator tested in other studies, but we obviously have no information on indicators that were not tested.

\section{Results}

A total of 11,351 titles and abstracts were identified. After review, and after removing duplicates, 217 abstracts were considered relevant to our study. From these, 94 articles were relevant, reviewed in full and evaluated for quality with the ISPOR checklist. ${ }^{8,9}$ Of these 94 articles, 26 passed the methodological quality review ${ }^{16-41}$ (Figure 1 ). The $\kappa$-statistic for agreement between the reviewers for the final articles was 0.73 . Even among approved studies, the methodological quality was low, with an average score of 16.8 out of a maximum of 27.

Of the 26 studies included for analysis, the most common follow-up duration was 12 months, for which 17 studies and 20 cohorts had data. Among these, with a total sample size of 1,522,203, 48.5\% (95\% confidence interval [CI] $47.7 \%-49.2 \%$ ) of patients were adherent to antihypertensive medications at 1 year of follow-up, with a range from $20 \%$ to $88 \%$. One study had a sample size of 725,220 , which contributed $47.6 \%$ of the total sample. Removal of this one large study resulted in an adherence level of $56.9 \%$ (95\% CI
$56.7 \%-57.1 \%$ ). This paper was also the only study conducted outside of North America and Europe with follow-up duration of 12 months. The two most common adherence measures were proportion of days covered and discontinuation, with adherence levels of $62.2 \%$ (95\% CI 61.9\%-62.5\%) for proportion of days covered and $55.1 \%$ (95\% CI 55.0\%-55.2\%) for discontinuation.

The second objective was to provide estimates of risk indicators associated with nonadherence to antihypertensive therapy. In total, the associations between 114 variables and nonadherence to antihypertensive medications were reviewed. In the end, nine variables were associated with nonadherence to antihypertensive medications, with five representing drug class and four from variables other than drug class (Table 1 and Figure 2).

For five studies and seven cohorts with a total sample size of $1,082,417$, patients who were dispensed diuretics, in comparison to ACEIs, were $36 \%$ more likely to be nonadherent (RR 1.36, 95\% CI 1.22-1.51). Among five studies and seven cohorts with a total sample size of 1,028,044, patients who were dispensed diuretics, in comparison to ARBs, were 47\% more likely to be nonadherent (RR 1.47, 95\% CI 1.27-1.70). For three studies and five cohorts with a total sample size of 295,512 , patients who were dispensed 
Table I Results of individual studies

\begin{tabular}{|c|c|c|c|c|}
\hline & $\begin{array}{l}\text { Rate } \\
\text { ratio }\end{array}$ & $95 \% \mathrm{Cl}$ & $\begin{array}{l}\text { Relative } \\
\text { weight }\end{array}$ & Homogeneity \\
\hline \multicolumn{5}{|l|}{ ACEls versus $A R B s$} \\
\hline Bloom ${ }^{19}$ & 1.19 & $1.03-1.32$ & 0.26 & \\
\hline Elliott et $\mathrm{al}^{23}$ & $\mathrm{I} .14$ & $1.09-1.20$ & 0.28 & \\
\hline Wogen et $\mathrm{al}^{33}$ & 1.45 & $1.43-1.47$ & 0.29 & \\
\hline Degli Esposti et $\mathrm{al}^{36}$ & 1.58 & $1.12-2.08$ & 0.16 & \\
\hline Pooled & 1.30 & I.10-I.54 & 1.00 & 0.000 \\
\hline \multicolumn{5}{|l|}{$C C B s$ versus $A R B s$} \\
\hline Sung et $\mathrm{al}^{38}$ & 1.10 & I.09-I.II & 0.29 & \\
\hline Elliott et $\mathrm{al}^{23}$ & 1.32 & $1.26-1.39$ & 0.28 & \\
\hline Wogen et $\mathrm{al}^{33}$ & 1.33 & $\mid .31-1.35$ & 0.29 & \\
\hline Degli Esposti et $\mathrm{al}^{36}$ & 2.07 & $1.57-2.73$ & 0.14 & \\
\hline Pooled & $\mathrm{I} .33$ & $1.16-1.54$ & 1.00 & 0.000 \\
\hline \multicolumn{5}{|c|}{ Diuretics versus ACEls } \\
\hline Elliott et $\mathrm{a}^{23}$ & 1.53 & $1.47-1.61$ & 0.14 & \\
\hline Taira et $\mathrm{al}^{25}$ & 1.49 & $1.40-1.60$ & 0.14 & \\
\hline Van Wijk et $a^{26}$ & 1.52 & $1.46-1.57$ & 0.14 & \\
\hline Van Wijk et $\mathrm{al}^{26}$ & 1.32 & $1.28-1.36$ & 0.15 & \\
\hline Van Wijk et $\mathrm{al}^{26}$ & 1.38 & $1.33-1.43$ & 0.14 & \\
\hline Friedman et $\mathrm{al}^{30}$ & 1.17 & $1.10-1.25$ & 0.14 & \\
\hline Sung et $\mathrm{al}^{38}$ & 1.16 & $1.14-1.17$ & 0.15 & \\
\hline Pooled & 1.36 & $|.22-| .5 \mid$ & 1.00 & 0.000 \\
\hline \multicolumn{5}{|l|}{ Diuretics versus ARBs } \\
\hline Degli Esposti et $\mathrm{al}^{36}$ & 2.62 & $1.99-3.46$ & 0.10 & \\
\hline Taira et $\mathrm{al}^{25}$ & 1.61 & $1.50-1.70$ & 0.15 & \\
\hline Van Wijk et $\mathrm{al}^{26}$ & 1.50 & $1.42-1.57$ & 0.15 & \\
\hline Van Wijk et al ${ }^{26}$ & $\mathrm{I} .45$ & $1.31-1.56$ & 0.15 & \\
\hline Van Wijk et $\mathrm{al}^{26}$ & 1.52 & $1.47-1.56$ & 0.15 & \\
\hline Friedman et $\mathrm{al}^{30}$ & 1.07 & $0.93-1.22$ & 0.14 & \\
\hline Sung et $\mathrm{al}^{38}$ & 1.16 & $1.14-1.17$ & 0.15 & \\
\hline Pooled & 1.47 & $1.27-1.70$ & 1.00 & 0.000 \\
\hline \multicolumn{5}{|c|}{ Diuretics versus $C C B s$} \\
\hline Friedman et $\mathrm{al}^{30}$ & 1.08 & $0.99-1.19$ & 0.19 & \\
\hline Taira et $\mathrm{al}^{25}$ & 2.01 & $1.90-2.20$ & 0.20 & \\
\hline Van Wijk et $a^{26}$ & 1.46 & $1.35-1.53$ & 0.20 & \\
\hline Van Wijk et al ${ }^{26}$ & 1.15 & $1.06-1.22$ & 0.20 & \\
\hline Van Wijk et $\mathrm{al}^{26}$ & 1.23 & $1.16-1.29$ & 0.20 & \\
\hline Pooled & 1.35 & $1.14-1.60$ & 1.00 & 0.000 \\
\hline \multicolumn{5}{|c|}{ Depression versus no depression } \\
\hline Rasmussen et al $^{16}$ & 2.13 & $1.44-3.14$ & 0.02 & \\
\hline Rasmussen et al ${ }^{16}$ & 1.81 & $1.07-3.07$ & 0.01 & \\
\hline Perreault et $\mathrm{al}^{24}$ & 0.93 & $0.85-1.02$ & 0.14 & \\
\hline Van Wijk et $a^{26}$ & 1.10 & $0.99-I .14$ & 0.19 & \\
\hline Van Wijk et $a^{26}$ & 1.14 & $1.05-1.25$ & 0.14 & \\
\hline Van Wijk et al ${ }^{26}$ & 1.03 & $0.94-1.12$ & 0.15 & \\
\hline Siegel et $\mathrm{al}^{29}$ & 1.16 & $1.14-1.18$ & 0.20 & \\
\hline Evans et $\mathrm{al}^{39}$ & 1.17 & $1.09-1.26$ & 0.16 & \\
\hline Pooled & I.II & $1.05-1.18$ & 1.00 & 0.000 \\
\hline \multicolumn{5}{|c|}{ Low income versus higher } \\
\hline Rasmussen et al $^{16}$ & 1.05 & $0.9 I-I .11$ & 0.09 & \\
\hline Rasmussen et al ${ }^{16}$ & 1.07 & $0.94-1.23$ & 0.06 & \\
\hline Perreault et $\mathrm{al}^{24}$ & 1.34 & $1.26-1.42$ & 0.09 & \\
\hline Van Wijk et $a^{26}$ & 0.94 & $0.86-1.02$ & 0.08 & \\
\hline Van Wijk et al ${ }^{26}$ & 1.19 & $1.15-1.23$ & 0.09 & \\
\hline Van Wijk et al ${ }^{26}$ & 1.05 & $1.01-1.10$ & 0.09 & \\
\hline Gogovor et $\mathrm{al}^{28}$ & 1.02 & $0.83-1.26$ & 0.04 & \\
\hline Gogovor et $\mathrm{al}^{28}$ & 1.26 & $1.1 \mathrm{I}-\mathrm{I} .42$ & 0.06 & \\
\hline
\end{tabular}

(Continued)
Table I (Continued)

\begin{tabular}{|c|c|c|c|c|}
\hline & $\begin{array}{l}\text { Rate } \\
\text { ratio }\end{array}$ & $95 \% \mathrm{Cl}$ & $\begin{array}{l}\text { Relative } \\
\text { weight }\end{array}$ & Homogeneity \\
\hline Friedman et $\mathrm{al}^{30}$ & 1.10 & $1.08-1.12$ & 0.10 & \\
\hline Corrao et $\mathrm{al}^{31}$ & 1.02 & $0.98-1.05$ & 0.09 & \\
\hline Wong et $\mathrm{al}^{37}$ & 1.22 & $1.15-1.29$ & 0.09 & \\
\hline Evans et $\mathrm{a}^{39}$ & 1.60 & $1.31-1.96$ & 0.04 & \\
\hline Rasmussen et $\mathrm{al}^{40}$ & 0.98 & $0.90-1.14$ & 0.09 & \\
\hline Pooled & 1.12 & $1.06-1.18$ & 1.00 & 0.000 \\
\hline \multicolumn{5}{|c|}{ Diabetics versus nondiabetics } \\
\hline Rasmussen et $\mathrm{al}^{16}$ & 0.98 & $0.68-1.22$ & 0.03 & \\
\hline Rasmussen et $\mathrm{al}^{16}$ & 1.16 & $0.85-1.38$ & 0.02 & \\
\hline Setoguchi et al ${ }^{17}$ & 1.03 & $1.00-1.06$ & 0.12 & \\
\hline Setoguchi et al ${ }^{17}$ & 1.03 & $0.99-1.06$ & 0.11 & \\
\hline Degli Esposti et al ${ }^{20}$ & 0.50 & $0.17-0.76$ & 0.04 & \\
\hline Perreault et $\mathrm{al}^{24}$ & 1.14 & $1.06-1.21$ & 0.09 & \\
\hline Taira et $\mathrm{a}^{25}$ & 1.13 & $1.10-1.20$ & 0.12 & \\
\hline Van Wijk et al ${ }^{26}$ & 1.01 & $0.92-1.09$ & 0.09 & \\
\hline Van Wijk et al ${ }^{26}$ & 1.03 & $1.00-1.14$ & 0.09 & \\
\hline Van Wijk et al ${ }^{26}$ & 1.17 & $1.10-1.24$ & 0.09 & \\
\hline Gogovor et $\mathrm{al}^{28}$ & 1.11 & $0.92-1.27$ & 0.04 & \\
\hline Gogovor et $\mathrm{al}^{28}$ & 1.19 & $1.07-1.29$ & 0.06 & \\
\hline Siegel et $\mathrm{al}^{29}$ & 1.02 & $0.99-1.04$ & 0.12 & \\
\hline Pooled & 1.07 & $1.02-1.11$ & 1.00 & 0.000 \\
\hline \multicolumn{5}{|l|}{ Black versus White } \\
\hline Setoguchi et $\mathrm{al}^{17}$ & 1.23 & $1.19-1.27$ & 0.15 & \\
\hline Setoguchi et a $\left.\right|^{17}$ & 1.09 & $1.06-1.13$ & 0.15 & \\
\hline Yang et $\mathrm{al}^{21}$ & 1.38 & $1.36-1.39$ & 0.15 & \\
\hline Shaya et $\mathrm{al}^{22}$ & 1.55 & $|.30-1.7|$ & 0.13 & \\
\hline Van Wijk et al ${ }^{26}$ & 1.42 & $1.19-1.66$ & 0.11 & \\
\hline Siegel et $\mathrm{al}^{29}$ & 1.08 & $1.07-1.09$ & 0.15 & \\
\hline Yang et $\mathrm{a}^{21}$ & 1.28 & $1.27-1.30$ & 0.15 & \\
\hline Pooled & 1.27 & $1.14-1.42$ & 1.00 & 0.000 \\
\hline
\end{tabular}

Abbreviations: $\mathrm{Cl}$, confidence interval; $\mathrm{ACEls}$, angiotensin-converting enzyme inhibitors; ARBs, angiotensin receptor blockers; CCBs, calcium channel blockers.

diuretics, in comparison to CCBs, were $35 \%$ more likely to be nonadherent (RR 1.35, 95\% CI 1.14-1.60). Pooling of four studies with a total sample size of 232,665 revealed that patients who were dispensed ACEIs, in comparison to ARBs, were $30 \%$ more likely to be nonadherent (RR $1.30,95 \%$ CI 1.10-1.54). Analysis of four studies with a total sample size of 936,162 showed that patients who were dispensed CCBs, in comparison to ARBs, were $33 \%$ more likely to be nonadherent (RR 1.33, 95\% CI 1.16-1.54).

There were five studies and eight cohorts that reviewed the association between depression or the use of antidepressants and nonadherence. With a total sample size of 206,673, patients who were either depressed or dispensed antidepressants were $11 \%$ more likely to be nonadherent to antihypertensive medications (RR 1.11, 95\% CI 1.05-1.18).

Comparing lowest-income to highest-income groups among nine studies and 13 cohorts with a sample size of 623,444 , we found that lower-income groups were $12 \%$ more likely to be nonadherent (RR 1.12, 95\% CI 1.06-1.18). 


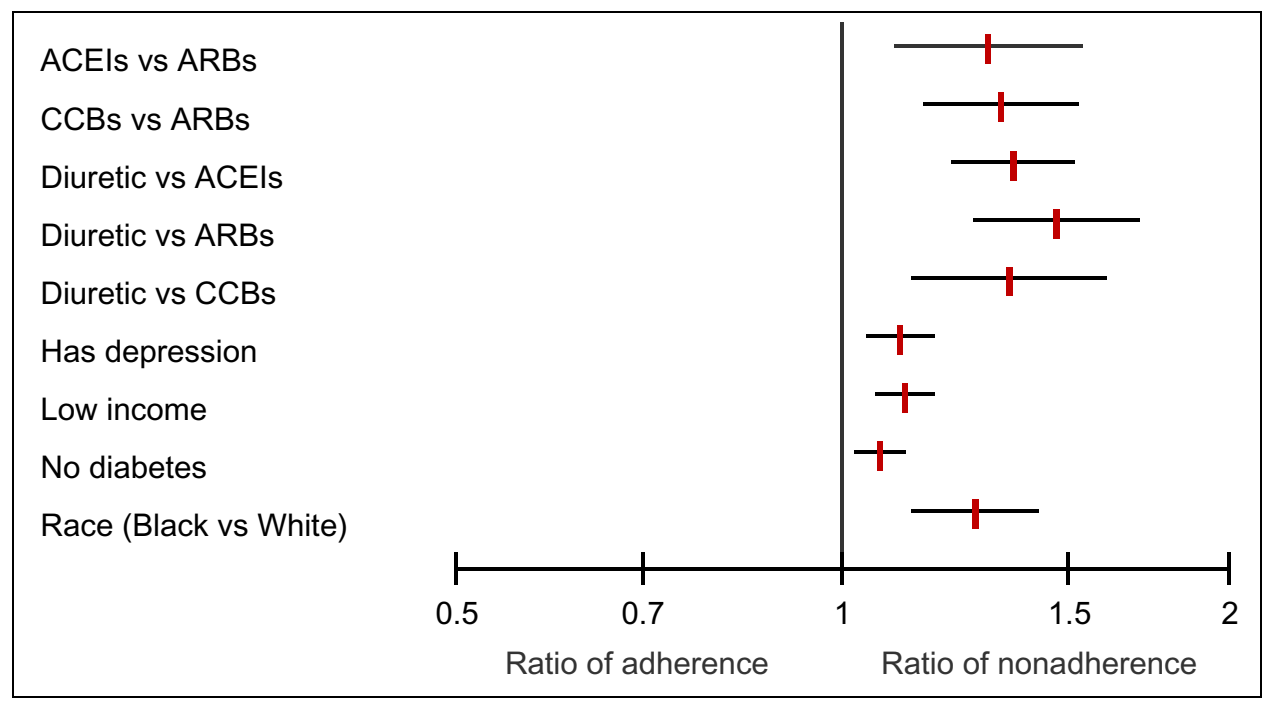

Figure 2 Covariates independently associated with nonadherence to antihypertensives.

Abbreviations: ACEls, angiotensin-converting enzyme inhibitors; ARBs, angiotensin receptor blockers; CCBs, calcium channel blockers.

Some studies reviewed race. Analysis of five studies and seven cohorts with a sample size of 1,771,428 revealed that residents who were of minority cultural status (African American race in American studies) in comparison to Caucasian (White) were $27 \%$ more likely to be nonadherent (RR 1.27, 95\% CI 1.14-1.42).

There were eight studies and 13 cohorts that reviewed the association between having diabetes and nonadherence. With a total sample size of 252,306 , patients without diabetes were $7 \%$ more likely to be nonadherent to antihypertensive medications (RR 1.07, 95\% CI 1.02-1.11).

There was no known association between the other 105 variables and nonadherence to antihypertensive medications. For example, patients with ischemic heart disease were only $3 \%$ more likely to be nonadherent to antihypertensive medications (RR 1.03, 95\% CI 0.90-1.18). As another example, patients with heart failure were $5 \%$ more likely to be nonadherent to antihypertensive medications (RR 1.05, $95 \%$ CI $0.98-1.12)^{42}$

Tests of homogeneity of variance for the nine variables associated with nonadherence were all $P<0.001$. This suggests highly significant heterogeneity between the studies. Stratification by country of origin and measure of adherence did not alter estimates to a significant degree. As well, sensitivity analysis of removing studies with the largest and smallest relative weights did not alter estimates to a significant degree. For example, removing non-North American and -European studies and removing the study with the largest sample size modified the odds ratio between diuretics and ACEIs from 1.36 ( $95 \%$ CI $1.22-1.51)$ to 1.40 (95\% CI $1.24-1.56)$.
Only three variables had negative estimates or results contrary to the other studies in the meta-analysis. Among eight cohorts that reviewed the association between depression or the use of antidepressants and nonadherence, one estimate was inconsistent with the other seven. For the thirteen cohorts that reviewed income, two estimates were inconsistent with the other eleven estimates. Among thirteen cohorts that reviewed the association between diabetes and nonadherence, two estimates were inconsistent with the other eleven.

All of the included papers are summarized in detail in Table S1.

\section{Discussion}

Of the 26 studies that were included in our study and passed methodological quality review, $48.5 \%$ (95\% CI $47.7 \%-49.2 \%$ ) of patients were adherent to antihypertensive medications at 1 year of follow-up. This clarifies the original WHO estimate that between $20 \%$ and $80 \%$ of patients receiving treatment for hypertension are adherent. ${ }^{1}$ This is simply a range from the lowest to the highest rates found during their review. Policy makers and health practitioners could assume that nonadherence is as low as $20 \%$ and therefore not a major problem. We quantified the value through meta-analysis in order to clarify the need for action.

Our study also provides estimates of known risk indicators associated with nonadherence to antihypertensive therapy. In total, the associations between 114 variables and nonadherence to antihypertensive medications were reviewed. In the end, nine variables were associated with 
nonadherence to antihypertensive medications: diuretics in comparison to ACEIs and ARBs and CCBs, ACEIs in comparison to ARBs, $\mathrm{CCBs}$ in comparison to $\mathrm{ARBs}$, those with depression or using antidepressants, not having diabetes, lower income status, and minority cultural status (African American race).

Although drug class has been shown to impact adherence, it is not clear if this is due to the properties of the drug class itself. One review suggests that differences may be due to patient selection or that out-of-pocket cost predicts drug choice. ${ }^{7}$ Also, the reality is that many patients are now started on more than one antihypertensive medication and combinations of drug classes. ${ }^{7}$ A recent paper found that differences in adherence by drug class were associated with their market availability, and that combination therapy of ARBs with diuretics had the highest proportion of adherence. ${ }^{43}$ Others would suggest that there are clinical differences like increased urination associated with diuretics. ${ }^{44}$ Regardless, our results were consistent with a meta-analysis that reviewed adherence of ARBs in comparison to other antihypertensive medications, although our study reviewed all drug classes. ${ }^{7}$

Depression is known to be associated with a threefoldgreater risk of nonadherence to medical treatment in general. ${ }^{45}$ A previous systematic literature review found that definitive conclusions could not be drawn between depression and nonadherence to antihypertensive therapy, possibly because five of the eight accepted studies included nonobjective and self-report measures to determine nonadherence. ${ }^{6}$ Our review addressed this limitation.

Not having diabetes was also associated with nonadherence, although the effect was small. Patients who have a low perceived risk of disease have been found less likely to adhere to their medications. ${ }^{5}$ Lower-income status might also increase nonadherence due to affordability, although lowincome status has also been associated with nonadherence to other health-seeking behaviors. ${ }^{46-49}$ The association between cultural status and adherence is likely to be due to confounding with income. ${ }^{50}$ In the US, African American cultural status is well known to be more likely associated with lower-income status at the population level. ${ }^{51}$

The main limitation of our meta-analysis was the inclusion of studies with wide variability and heterogeneity in measuring and defining adherence. Second, although our meta-analysis identified nine variables associated with nonadherence to antihypertensive medications, it remains unclear as to what extent adherence would be improved if these variables were addressed. Third, our interpretation is limited to variables reviewed. It is likely that other untested associations exist.

\section{Conclusion}

The known effectiveness of interventions for enhancing chronic disease medication adherence remains surprisingly weak. ${ }^{3}$ It is possible that this lack of effectiveness is due to not really knowing the risk indicators of nonadherence. This study provides some insight into factors associated, and not associated, with nonadherence to antihypertensive medications.

In summary, it is likely that effective ways to help patients follow medical treatments could have far larger effects on health outcomes than any individual treatment. The first step is to know the extent of nonadherence in patients and populations. The second is to have some idea as to what variables are associated with nonadherence.

\section{Acknowledgment}

Thank you to Dr David Blackburn from the College of Pharmacy and Nutrition at the University of Saskatchewan.

\section{Disclosure}

MWA's student position at the University of Saskatchewan is funded through unrestricted financial support from the Government of Saskatchewan's Ministry of Health, which in turn obtained unrestricted financial support from AstraZeneca Canada, Merck Frosst/Schering, and Pfizer Canada. None of these sponsors had input into the drafting or submission of this manuscript. ML reports no conflicts of interest in this work.

\section{References}

1. World Health Organization. Adherence to Long-Term Therapies: Evidence for Action. Geneva: WHO;2003.

2. Law MR, Morris JK, Wald NJ. Use of blood pressure lowering drugs in the prevention of cardiovascular disease: meta-analysis of 147 randomised trials in the context of expectations from prospective epidemiological studies. BMJ. 2009;338:b1665.

3. Haynes RB, Yao X, Degani A, Kripalani S, Garg A, McDonald HP. Interventions for enhancing medication adherence. Cochrane Database Syst Rev. 2005:CD000011.

4. Cutler DM, Everett W. Thinking outside the pillbox - medication adherence as a priority for health care reform. $N$ Engl J Med. 2010;362:1553-1555.

5. Lemstra M, Blackburn DF, Crawley A, Fung R. Proportion and risk indicators of non-adherence to statin therapy: a meta-analysis. Can J Cardiol. 2012;28(5):574-580.

6. Eze-Niliam CM, Thombs BD, Lima BB, Smith CG, Ziegelstein RC. The association of depression with adherence to antihypertensive medications: a systematic review. J Hypertension. 2010;28:1785-1795.

7. Kronish IM, Woodward M, Sergie Z, Ogedegbe G, Falzon L, Mann DM. Meta-analysis: impact of drug class on adherence to antihypertensives. Circulation. 2011;123:1611-1621.

8. Peterson AM, Nau DP, Cramer JA, Benner J, Gwadry-Sridhar F, Nichol M. A checklist for medication compliance and persistence studies using retrospective databases. Value Health. 2007;10:3-12.

9. Motheral B, Brooks J, Clark MA, et al. A checklist for retrospective database studies - report of the ISPOR task force on retrospective databases. Value Health. 2003;6:90-97. 
10. Alsabbagh W, Lemstra M, Eurich D, et al. Socioeconomic Status and Non Adherence to Anti-Hypertensive Drugs: A Systematic Review and Meta-Analysis. Value in Health. 2014. Available from: http:// www.ispor.org/publications/value/articlesinpress.asp. Accessed February 4, 2014.

11. Douglas, GA. Practical Statistics for Medical Research. 1st ed. New York: Chapman and Hall; 1991.

12. Fleiss Jl. The statistical basis of meta-analysis. Stat Methods Med Res. 1993;2:121-145.

13. Huedo-Medina TB, Sánchez-Meca J, Marín-Martínez F, Botella J. Assessing heterogeneity in meta-analysis: Q statistic or I2 index? Psychol Methods. 2006;11:193-206.

14. Higgins JP, Green S. Cochrane Handbook for Systematic Reviews of Interventions. Chichester, UK: John Wiley \& Sons; 2006.

15. DerSimonian R, Laird N. Meta-analysis in clinical trials. Control Clin Trials. 1986;7:177-188.

16. Rasmussen JN, Chong A, Alter DA. Relationship between adherence to evidence-based pharmacotherapy and long-term mortality after acute myocardial infarction. JAMA. 2007;297:177-186.

17. Setoguchi S, Choudhry NK, Levin R, Shrank WH, Winkelmayer WC Temporal trends in adherence to cardiovascular medications in elderly patients after hospitalization for heart failure. Clin Pharmacol Ther. 2010;88:548-554.

18. Monane M, Bohn RL, Gurwitz JH, Glynn RJ, Levin R, Avorn J. The effects of initial drug choice and comorbidity on antihypertensive therapy compliance: results from a population-based study in the elderly. Am J Hypertens. 1997; 10:697-704.

19. Bloom BS. Continuation of initial antihypertensive medication after 1 year of therapy. Clin Ther. 1998;20:671-681.

20. Degli Esposti L, Degli Esposti E, Valpiani G, et al. A retrospective, population-based analysis of persistence with antihypertensive drug therapy in primary care practice in Italy. Clin Ther. 2002;24:1347-1357; discussion 1346

21. Yang Y, Thumula V, Pace PF, Banahan BF 3rd, Wilkin NE, Lobb WB. Predictors of medication nonadherence among patients with diabetes in Medicare part D programs: a retrospective cohort study. Clin Ther. 2009;31:2178-2188; discussion 2150-2151.

22. Shaya FT, Du D, Gbarayor CM, Frech-Tamas F, Lau H, Weir MR. Predictors of compliance with antihypertensive therapy in a high-risk Medicaid population. J Natl Med Assoc. 2009;101:34-39.

23. Elliott WJ, Plauschinat CA, Skrepnek GH, Gause D. Persistence, adherence, and risk of discontinuation associated with commonly prescribed antihypertensive drug monotherapies. J Am Board Fam Med. 2007;20:72-80.

24. Perreault S, Lamarre D, Blais L, et al. Persistence with treatment in newly treated middle-aged patients with essential hypertension. Ann Pharmacother. 2005;39:1401-1408.

25. Taira DA, Gelber RP, Davis J, Gronley K, Chung RS, Seto TB. Antihypertensive adherence and drug class among Asian Pacific Americans. Ethn Health. 2007;12:265-281.

26. van Wijk BL, Shrank WH, Klungel OH, Schneeweiss S, Brookhart MA, Avorn J. A cross-national study of the persistence of antihypertensive medication use in the elderly. J Hypertens. 2008; 26:145-153.

27. Lamb D, Eurich D, McAlister F, et al. Changes in adherence to evidence-based medications in the first year after initial hospitalization for heart failure: observational cohort study from 1994 to 2003. Circ Cardiovasc Qual Outcomes. 2009;2:228-235.

28. Gogovor A, Dragomir A, Savoie M, Perreault S. Comparison of persistence rates with angiotensin-converting enzyme inhibitors used in secondary and primary prevention of cardiovascular disease. Value Health. 2007;10:431-441.

29. Siegel D, Lopez J, Meier J. Antihypertensive medication adherence in the Department of Veterans Affairs. Am J Med. 2007;120:26-32.

30. Friedman O, McAlister FA, Yun L, Campbell NR, Tu K. Antihypertensive drug persistence and compliance among newly treated elderly hypertensives in Ontario. Am J Med. 2010;123:173-181.
31. Corrao G, Zambon A, Parodi A, et al. Do socioeconomic disparities affect accessing and keeping antihypertensive drug therapy? Evidence from an Italian population-based study. J Hum Hypertens. 2009;23:238-244.

32. Eagle KA, Kline-Rogers E, Goodman SG, et al. Adherence to evidencebased therapies after discharge for acute coronary syndromes: an ongoing prospective, observational study. Am J Med. 2004;117: 73-81.

33. Wogen J, Kreilick CA, Livornese RC, Yokoyama K, Frech F. Patient adherence with amlodipine, lisinopril, or valsartan therapy in a usual-care setting. J Manag Care Pharm. 2009;9:424-429.

34. Yang Y, Thumula V, Pace PF, Banahan BF 3rd, Wilkin NE, Lobb WB. Nonadherence to angiotensin-converting enzyme inhibitors and/ or angiotensin II receptor blockers among high-risk patients with diabetes in Medicare part D programs. J Am Pharm Assoc. 2010;50: 527-531.

35. Kramer JM, Hammill B, Anstrom KJ, et al. National evaluation of adherence to beta-blocker therapy for 1 year after acute myocardial infarction in patients with commercial health insurance. Am Heart $J$. 2006;152:454. e1-e8.

36. Degli Esposti E, Sturani A, Di Martino M, et al. Long-term persistence with antihypertensive drugs in new patients. J Hum Hypertens. 2002; $16: 439-444$

37. Wong MC, Jiang JY, Su X, Wang H, Tang JL, Griffiths SM. Individuals at risk of beta-blocker discontinuation: a cohort study in 19,177 Chinese patients. Clin Res Cardiol. 2010;99:277-284.

38. Sung SK, Lee SG, Lee KS, Kim DS, Kim KH, Kim KY. First-year treatment adherence among outpatients initiating antihypertensive medication in Korea: results of a retrospective claims review. Clin Ther. 2009;31:1309-1320.

39. Evans CD, Eurich DT, Remillard AJ, Shevchuk YM, Blackburn D. Firstfill medication discontinuations and nonadherence to antihypertensive therapy: an observational study. Am J Hypertens. 2012;25:195-203.

40. Rasmussen JN, Gislason GH, Rasmussen S, et al. Use of statins and beta-blockers after acute myocardial infarction according to income and education. J Epidemiol Community Health. 2007;61:1091-1097.

41. Carrao G, Parodi A, Zambon A, et al. Reduced discontinuation of antihypertensive therapy by two-drug combination as first step. Evidence from daily life practice. J Hypertens. 2010;28:1584-1590.

42. World Health Organization. ICD-10: International Statistical Classification of Diseases and Related Health Problems. New York: WHO; 2008

43. Evans CD, Eurich DT, Lu X, Remillard AJ, Shevchuk YM, Blackburn D. The association between market availability and adherence to antihypertensive medications: an observational study. Am J Hypertens. 2013;26:180-190.

44. Canadian Pharmacists Association. Compendium of Pharmaceuticals and Specialties: Thiazide Diuretics - Product Monograph. Ottawa: Canadian Pharmacists Association; 2012.

45. DiMatteo MR, Lepper HS, Croghan TW. Depression is a risk factor for noncompliance with medical treatment: a meta-analysis of the effects of anxiety and depression on patient adherence. Arch Intern Med. 2000;160:2101-2107.

46. Osterberg L, Blaschke T. Adherence to medication. $N$ Engl J Med. 2005;353:487-497.

47. O'Malley AS, Forrest CB, Mandelblatt J. Adherence of low-income women to cancer screening recommendations. $J$ Gen Intern Med. 2002;17:144-154

48. Celano M, Geller RJ, Phillips KM, Ziman R. Treatment adherence among low-income children with asthma. J Pediatr Psychol. 1998;23:345-349.

49. Orlandi MA. Promoting health and preventing disease in health care settings: an analysis of barriers. Prev Med. 1987;16:119-130.

50. Diamond J. Guns, Germs, and Steel: The Fates of Human Societies. New York: WW Norton; 1999.

51. US Census Bureau. People below poverty level and below 125 percent of poverty level by race and Hispanic origin: 1980 to 2009. 2012. Available from: http://www.census.gov/compendia/statab/2012/tables/12s0711. pdf. Accessed January 24, 2013. 
Patient Preference and Adherence

Dovepress

\section{Publish your work in this journal}

Patient Preference and Adherence is an international, peer-reviewed, open access journal focusing on the growing importance of patient preference and adherence throughout the therapeutic continuum. Patient satisfaction, acceptability, quality of life, compliance, persistence and their role in developing new therapeutic modalities and compounds to

optimize clinical outcomes for existing disease states are major areas of interest. This journal has been accepted for indexing on PubMed Central. The manuscript management system is completely online and includes a very quick and fair peer-review system. Visit http://www.dovepress.com/ testimonials.php to read real quotes from published authors.

Submit your manuscript here: http://www.dovepress.com/patient-preference-and-adherence-journal 